\title{
Validated HPTLC Method for the Determination of Nintedanib in Bulk Drug ${ }^{\dagger}$
}

\author{
Debanchal Dutta ${ }^{1}$, Soumyajit Das ${ }^{2}$ and Manik Ghosh 1,* \\ 1 Birla Institute of Technology, Mesra, Ranchi, Jharkhand 835215, India; debanchal123@gmail.com \\ 2 Bristol Myers Squibb, E. City Phase-I, Bengaluru, Karnataka 560100, India; soudas08@gmail.com \\ * Correspondence: manik@bitmesra.ac.in; Tel.: +91-6512276247; Fax: +91-6512275401 \\ + Presented at the 22nd International Electronic Conference on Synthetic Organic Chemistry, 15 November- \\ 15 December 2018; Available Online: https://sciforum.net/conference/ecsoc-22.
}

Published: 14 November 2018

\begin{abstract}
A simple, rapid, precise and accurate High-Performance Thin Layer Chromatography (HPTLC) method was developed and validated for the estimation of Nintedanib, a novel tyrosine kinase inhibitor used in idiopathic pulmonary fibrosis, in bulk drug. Chromatography was carried out using silica gel $60 \mathrm{~F}_{254}$ Thin Layer Chromatography (TLC) plate and mobile phase Chloroform: Methanol in the ratio 7:3 v/v. The densitometric determination was done at $386 \mathrm{~nm}$. Regression analysis data for the calibration plot were indicative of a good linear relationship between response and concentration over the range of $800-3200 \mathrm{ng} / \mathrm{band}$. The variance (r) was found to be 0.999 . The Limit of Detection (LOD) and Limit of Quantitation (LOQ) were found to be $83.357 \mathrm{ng} / \mathrm{band}$ and $252.599 \mathrm{ng} / \mathrm{band}$ respectively. The method was validated according to the International Council for Harmonisation of Technical Requirements for Pharmaceuticals for Human Use [ICH Q2(R1)] guideline. The method was precise and accurate with \%RSD 0.5323 (intraday) and 0.6939 (interday) respectively and percentage recoveries in the range $99.65-101.43 \%$.
\end{abstract}

Keywords: Nintedanib; HPTLC; idiopathic pulmonary fibrosis

\section{Introduction}

Nintedanib (NTB), an inhibitor of tyrosine kinase, marketed under the brand names "Ofev" and "Vargatef" is used to treat Idiopathic Pulmonary Fibrosis (IPF). Idiopathic Pulmonary fibrosis is a rare chronic lung disease identified by a progressive and irreversible loss of lung function, dyspnea, and cough. In this disease, lung tissues present deep inside becomes thick and stiff or scarred with time. With the thickening of lung tissues, exchange of oxygen in blood decreases and as a result brain and other organs start to fail due to the scarcity of oxygen. Symptoms include gradual onset of shortness of breath and a dry cough, tiredness and nail clubbing. IPF is often accompanied by complications like pulmonary hypertension, heart failure, pneumonia, and pulmonary embolism.

NTB is chemically methyl (3z)-3-[[4-[methyl-[2-(4-methylpiperazine-1yl) acetyl] amino] anilino] phenyl methylidene]-2-oxo-1H-indole-6-carboxylate. It acts by selectively binding to the intracellular ATP binding pocket of fibroblast growth factor receptor (FGFRs), vascular endothelial growth factor receptor (VEGFRs) and platelet-derived growth factor receptor (PDGFRs) and thereby inhibiting them. Generally, IPF is incurable, the available drugs just reduce the advancement of the disease and slow down the drop-in lung functioning by obstructing the fibrotic process signaling pathways.

Literature review suggest that various methods involving UPLC, LC-MS, UV are already reported for the estimation of NTB in bulk drug, formulation, rat plasma and human plasma. Lin et al. (2016) worked on simultaneous determination of NTB and its metabolite in rat plasma by UPLCMS/MS. Darwish et al. (2016) performed a rapid validated LC-MS for NTB quantification in human plasma. However, to date a validated HPTLC method for the estimation of NTB in bulk drug has not 
been reported. The current manuscript is an attempt to report a validated HPTLC method as per ICH Q2(R1) guidelines for estimation of NTB. This study was designed to develop a simple, rapid, precise and accurate HPTLC method for determination of NTB in bulk drug and to validate such as per ICH guidelines.

\section{Materials and Methods}

\subsection{Materials}

Pure NTB API was received as gift sample from MSN Laboratories Private Ltd., India. HPLC grade solvents were procured from Spectrochem Pvt. Ltd. Mumbai, India.

\subsection{Instrumentation}

A Hamilton microliter syringe (Linomat syringe 659.0014, Hamilton-Bonaduz Schweiz, Camag, Switzerland), pre-coated silica gel aluminum Plate $60 \mathrm{~F} 254,(20 \mathrm{~cm} \times 10 \mathrm{~cm}, 100 \mathrm{~m}$ thickness; E. Merck, Darmstadt, Germany), Linomat 5 sample applicator (Camag, Muttenz, Switzerland), twin-trough chamber $(20 \mathrm{~cm} \times 10 \mathrm{~cm}$; Camag, Muttenz, Switzerland), TLC Visualizer 2 (Camag, Muttenz, Switzerland) for photo documentation, and a TLC scanner 4 (Camag, Switzerland) operated by the visionCATS software (version 2.5, Camag, Muttenz, Switzerland) were used while performing the study. Electronic analytical balance (AUW 220, Sartorius Corp., Göttingen, Germany) was used for accurate weighing of drug.

\subsection{Preparation of Standard Solution}

Standard NTB was accurately weighed (100 mg) and was transferred to a $100 \mathrm{~mL}$ volumetric flask. NTB was dissolved in methanol and the volume was made up to the mark to obtain a stock solution of $1000 \mu \mathrm{g} / \mathrm{mL}$ solution. $20 \mathrm{~mL}$ was pipetted out from the prepared stock solution and was further diluted with methanol to obtain working concentration of $200 \mathrm{ng} / \mu \mathrm{L}$.

\subsection{Mobile Phase Optimization}

The mobile phase was optimized to Chloroform: Methanol in the ratio of 7:3 after several trials.

\subsection{Chromatographic Procedure}

Different working concentrations of NTB were prepared from the standard solution. Bands with bandwidth of $8 \mathrm{~mm}$ were applied on a pre-coated silica gel 60 GF254 aluminum plates with sample applicator Linomat 5 . Twin-trough glass chamber was used for linear ascending development. The mobile phase comprised of chloroform: methanol $(7: 3 v / v)$ and 20 min was set as the chamber saturation time at room temperature. The development was allowed till $80 \mathrm{~mm}$. After the development, plates were dried with the help of an air dryer and scanned using densitometer with Camag TLC scanner 4 using visionCATS software. All measurements were taken at $386 \mathrm{~nm}$ in the reflectance-absorbance mode, with $6.00 \mathrm{~mm} \times 0.45 \mathrm{~mm}$ (micro) slit dimension, $20 \mathrm{~mm} / \mathrm{s}$ scanning speed, and $100 \mathrm{~m} /$ step data resolution. Reported areas of respective bands were used for calculation.

\subsection{Method Validation}

Developed HPTLC method was validated for linearity, precision, accuracy, limit of detection (LOD), limit of quantitation (LOQ) and robustness in accordance with ICH Q2(R1) guideline.

Linearity: Concentrations from 800-3200 ng/band having same volume $(8 \mu \mathrm{L})$ of NTB were applied in triplicate on HPTLC plate. A graph of obtained peak areas versus the corresponding concentration were plotted and evaluated using linear regression analysis.

Sensitivity: LOD and LOQ of the method was calculated by the standard deviation of the obtained peak areas. A known concentration was taken and spotted six times on HPTLC plate. Slope of the calibration curve was obtained after performing linearity. Calculation was done using the formula stated by ICH in its guideline: 


$$
\begin{gathered}
\text { Limit of Detection }(\mathrm{LOD})=3.3 \times \sigma / \mathrm{S} \\
\text { Limit of Quantitation }(\mathrm{LOQ})=10 \times \sigma / \mathrm{S}
\end{gathered}
$$

where, ' $\sigma$ ' is the standard deviation of the $y$-intercept of the regression line, and ' $S$ ' is the slope of the calibration curve.

Precision: Precision was determined by performing intraday and interday precision studies. Intraday precision was evaluated by taking differently weighed working concentration of NTB $(1600 \mathrm{ng} / \mathrm{band})$ and spotting in triplicates on the same day and interday precision was performed in the same way using the above-mentioned concentration in three different days. Then \%RSD was calculated from the obtained peak areas.

Accuracy: The accuracy of the method was performed using standard addition method. Standard NTB was spiked into the standard solution at $80 \%, 100 \%$ and $120 \%$ levels consisting $1280 \mathrm{ng} / \mathrm{band}$, $1600 \mathrm{ng} / \mathrm{band}$ and $1920 \mathrm{ng} / \mathrm{band}$ respectively. Then based on the measured peak areas \% recovery was calculated which was found to be within $100 \pm 2 \%$.

Robustness: Small and deliberate variations in method parameters like change in the mobile phase ratio and saturation time were made and their effect on response was observed. Finally, \%RSD was calculated

\section{Results and Discussion}

\subsection{Wavelength Selection}

The sensitivity of the method relies on the selection of correct wavelength. The developed plate was scanned in densitometer under reflectance mode in UV-Visible region from 200-700 nm using Camag TLC scanner 4. A clear resolute peak was obtained at $386 \mathrm{~nm}$ and was chosen as the working wavelength.

\subsection{Method Optimization}

Optimization of chromatographic conditions were done to obtain a method appropriate for NTB determination in bulk drug. At preliminary stage, various combinations of mobile phase and in different ratios such as Chloroform: Ethyl acetate (7:3, 8:2, 9:1) and Chloroform: Methanol (9:1, 8:2, 7:3) were tested with 20 min saturation time. Finally, mobile phase Chloroform: Methanol (7:3) was chosen for performing the experiment since the $R_{f}(0.58 \pm 0.02)$ and the resolution of the band were satisfactory compared to the above tested combinations.

\subsection{Method Validation}

"Linearity of an analytical procedure is its ability (within a range) to provide a response directly proportional to the concentration of the analyte". NTB showed good correlation coefficient $\left(\mathrm{r}^{2}=0.999\right)$ in the concentration range of $800-3200 \mathrm{ng} / \mathrm{band}$ with equation $\mathrm{y}=0.7256 \mathrm{x}+1954.4$ (Figure 1). 


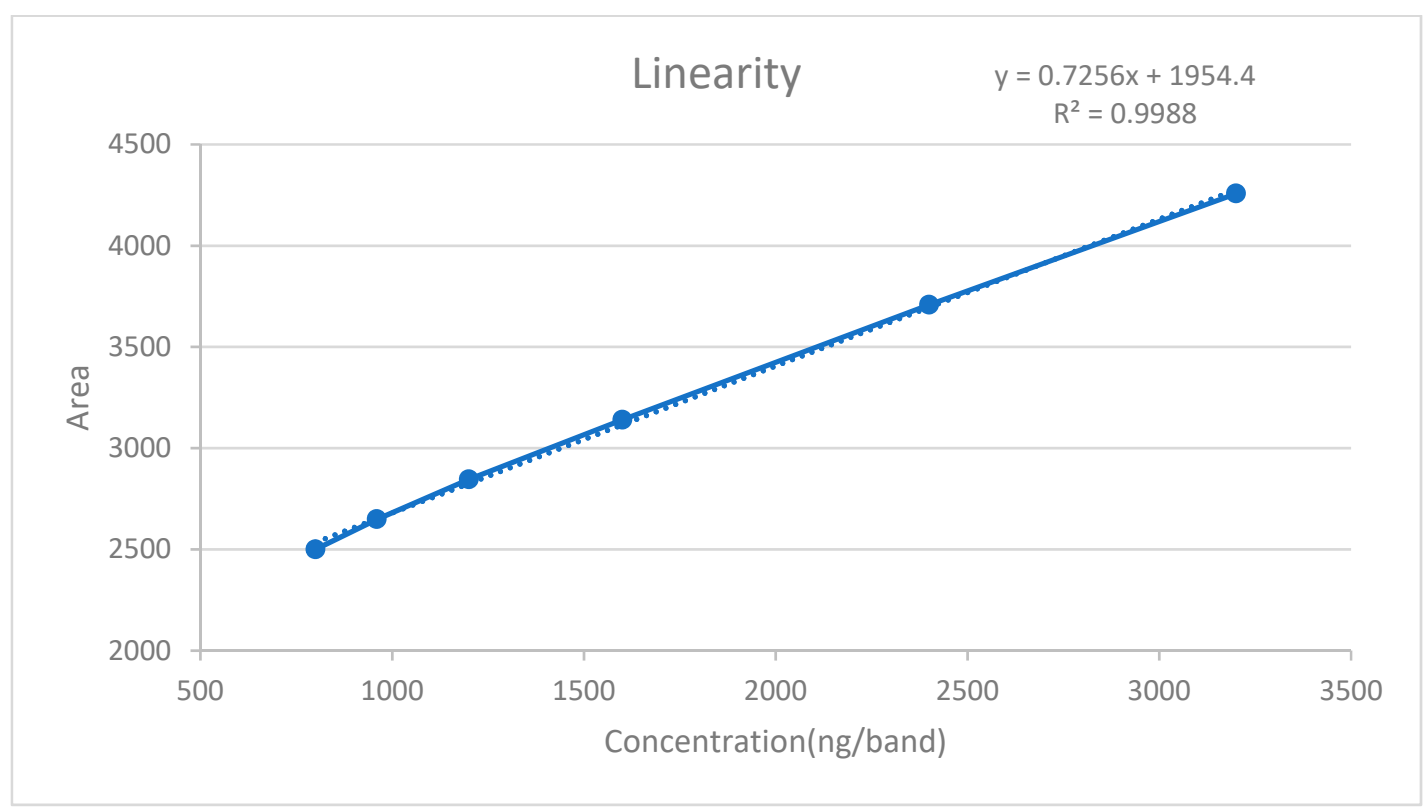

Figure 1. Linearity of Nintedanib from $800-3200 \mathrm{ng} / \mathrm{band} ; \mathrm{y}=0.7256 \mathrm{x}+1954.4 ; \mathrm{r}^{2}=0.999$.

Limit of Detection (LOD) and Limit of Quantitation ( $L O Q$ ) for NTB were obtained as $83.357 \mathrm{ng} / \mathrm{band}$ and $252.599 \mathrm{ng} / \mathrm{band}$ respectively thereby indicating the developed method's sensitivity. Intraday and Interday Precision was performed for precision studies. In intraday precision, the experiment was performed three times in a day by spotting working concentration in triplicates. Interday precision was performed by repeating the experiment in the same above-mentioned manner in different days. $\%$ RSD of the observed peak areas were calculated for both intraday (Table 1) and interday precision (Table 2) and was obtained as $0.303-0.682$ and $0.343-1.114$ respectively.

Table 1. Intraday precision of NTB $(n=3)$.

\begin{tabular}{ccccccc}
\hline Concentration (ng/band) & & Area & & Average Area & SD & \%RSD \\
\hline 1600 & 3151 & 3132 & 3140 & 3141.00 & 09.539 & 0.303 \\
1600 & 3179 & 3155 & 3136 & 3156.67 & 21.548 & 0.682 \\
1600 & 3149 & 3177 & 3162 & 3162.67 & 14.011 & 0.443 \\
\hline
\end{tabular}

Table 2. Interday precision of NTB ( $\mathrm{n}=3)$; Concentration $1600 \mathrm{ng} / \mathrm{band}$.

\begin{tabular}{ccccccc}
\hline Day & & Area & & Average Area & SD & \%RSD \\
\hline Day 1 & 3141 & 3156 & 3162 & 3153.00 & 10.817 & 0.343 \\
Day2 & 3138 & 3166 & 3121 & 3141.67 & 22.723 & 0.723 \\
Day 3 & 3168 & 3114 & 3180 & 3154.00 & 35.157 & 1.114 \\
\hline
\end{tabular}

Accuracy was performed by spiking standard NTB at $80 \%, 100 \%$ and $120 \%$ concentration levels into the standard solution. \% recoveries were calculated and was obtained as $99.65 \%$ to $101.43 \%$, which was within the acceptable range of $100 \pm 2 \%$ (Table 3 ).

Table 3. Accuracy of NTB.

\begin{tabular}{ccccc}
\hline \multirow{2}{*}{ Sample } & \multirow{2}{*}{ \% of Nominal } & \multicolumn{2}{c}{ Standard (ng/band) } & \multirow{2}{*}{ \% Recovery } \\
\cline { 3 - 4 } & & Spike & Found & \multirow{2}{*}{. } \\
\hline 1 & 80 & 1280 & 1292.127 & 100.95 \\
2 & 100 & 1600 & 1622.876 & 101.43 \\
3 & 120 & 1920 & 1913.201 & 99.65 \\
\hline
\end{tabular}


Robustness was performed by making small and deliberate changes in the mobile phase ratio and saturation time and their corresponding response were recorded. \%RSD was calculated and was found within the acceptable range of less than $2 \%$ (Table 4 ).

Table 4. Robustness with change in mobile phase ratio and saturation time.

\begin{tabular}{cccc}
\hline \multicolumn{4}{c}{ Change in Mobile Phase Ratio (Chloroform:Methanol: 7:3 \pm 0.2) } \\
\hline Solvent Ratio & $\mathbf{R}_{\mathbf{f}}$ & Area \pm SD & \%RSD \\
\hline $6.8: 3.2$ & $0.58 \pm 0.02$ & $3142.83 \pm 17.81$ & 0.566 \\
$7.2: 2.8$ & $0.58 \pm 0.02$ & $3152.50 \pm 28.27$ & 0.896 \\
\hline \multicolumn{4}{c}{ Change in Saturation Time (20 min \pm 2 min) } \\
\hline 18 & $\mathbf{R}_{\mathrm{f}}$ & Area \pm SD & \%RSD \\
\hline 22 & $0.58 \pm 0.01$ & $3147.00 \pm 28.69$ & 0.911 \\
\hline
\end{tabular}

\section{Conclusions}

The present study establishes a simple, precise, accurate and robust validated HPTLC method, suitable for estimation of NTB in bulk drug.

Acknowledgments: Authors are thankful to MSN Laboratories Pvt. Ltd., India for supplying the gift sample and Central Instrumentation Facility, BIT Mesra, Ranchi for HPTLC facilities.

\section{References}

1. Kamble, A.Y.; Mahadik, M.; Khatal, L.; Dhaneshwar, S.R. Validated HPLC and HPTLC Method for Simultaneous Quantitation of Amlodipine Besylate and Olmesartan Medoxomil in Bulk Drug and Formulation. Anal. Lett. 2010, 43, 251-258.

2. Lin, D.; Qiao, L.M.; Zhang, Y.N.; Liu, Y.; Liu, X.S. Simultaneous determination of nintedanib and its metabolite by UPLC-MS/MS in rat plasma and its application to a pharmacokinetic study. J. Pharm. Biomed. Anal. 2016, 117, 173-177.

3. Kleinschmidt, G. In Method Validation in Pharmaceutical Analysis. A Guide to Best Practice; Ermer, J., Miller, J.H.M., Eds.; Wiley-VCH Verlag GmbH \& Co. KGaA: Weinheim, Germany, 2005.

4. Darwish, H.W.; Attwa, M.W.; Kadi, A.A. Rapid validated liquid chromatographic method coupled with Tandem mass spectrometry for quantification of nintedanib in human plasma. Trop. J. Pharm. Res. 2016, 15, 2467-2473.

5. International Council for Harmonisation of Technical Requirements for Pharmaceuticals for Human Use. ICH Q2 (R1): Validation of Analytical Procedures: Text and Methodology; ICH Secretariat: Geneva, Switzerland, 2005.

6. Fodor, K.F.; Renger, B.; Vegh, Z. The frustrated reviewer-recurrent failures in manuscript describing validation of quantitative TLC/HPTLC procedures for analysis of pharmaceuticals. J. Planar Chromatogr. 2010, 23, 173-179.

7. Shah, P.; Patel, J.; Patel, K.; Gandhi, T. Development and validation of an HPTLC method for the simultaneous estimation of Clonazepam and Paroxetine hydrochloride using a DOE approach. J. Taibah Univ. Sci. 2017, 11, 121-132.

8. Venkatachalam, V.S. Chatterjee, Stability-indicating high-performance thin layer chromatography determination of Paroxetine hydrochloride in bulk drug and pharmaceutical formulations. Anal. Chim. Acta 2007, 598, 312-317.

(C) 2019 by the authors. Licensee MDPI, Basel, Switzerland. This article is an open access article distributed under the terms and conditions of the Creative Commons Attribution (CC BY) license (http://creativecommons.org/licenses/by/4.0/). 